\title{
INFLUENCE OF THE IONOSPHERIC DELAY ON DESIGNATION OF AN AIRCRAFT POSITION
}

The article presents and describes research results concerning determination of an impact of the ionospheric correction upon the positioning accuracy of an aircraft. The main objective of examinations was to verify three ionospheric models (the Klobuchar model, SBAS model and IONEX model) in determining aircraft coordinates. In the framework of the conducted simulations, the authors determined the aircraft coordinates by means of the SPP code method in the GPS system. The article presents a comparison of the determined aircraft coordinates in the SPP code method in relation to an accurate solution in the RTK-OTF differential technique. Based on the obtained results, it was found that e use of the SBAS and IONEX model is exploited to improve the positioning accuracy of an aircraft in relation to the Klobuchar model, from $20 \%$ to $72 \%$, in the geocentric XYZ frame. The obtained findings of a simulation indicate that the ionospheric correction in the SBAS and IONEX models may be used to improve the performance of aircraft coordinates in air navigation.

Keywords: ionospheric delay, GPS, aircraft position, Klobuchar model, SBAS model, IONEX model

\section{Introduction}

Use of the GPS satellite technology in aviation leads to designation of numerous systematic errors in satellite measurements. In general, the systematic GPS errors can be divided in geometry errors of the satellite-receiver system, errors associated with an accurate transfer of time and atmospheric errors [1]. Among the atmospheric errors it is possible to differentiate the tropospheric delay error and the ionospheric delay error.

The previous scientific investigations of determination of the ionospheric delay in aviation are mostly concerned with:

- impact of the ionospheric scintillation upon availability parameters and reliability of the GPS positioning within the approach procedures LPV-200 [2],

- determination of the slant value of the ionospheric delay STEC in kinematic measurements in aircraft positioning in aviation [3],

- determination of the slant value of the ionospheric delay STEC in the GPS single-frequency differential measurements in aircraft positioning in aviation [4],

- developing a methodology of determining the ionospheric delay STEC in single frequency code-phase GPS measurements within the NPA procedure and the APV indirect procedure [5],

- determination of the ionospheric delay in the GPS measurements within the GBAS augmentation system in air transport [6-11].

The problem of modelling the ionospheric delay in aviation is a huge challenge for scientists who are primarily focused on air navigation. In Poland, in which the air traffic is steadily increasing, there is a need to develop accurate models of the ionospheric delay as well as specifying an influence of this phenomenon on the positioning of an aircraft. Within the research conducted in Poland for modelling of the ionospheric delay, the Klobuchar and SBAS models were used for the EGNOS system [12-14]. In the above-mentioned works, value of the ionospheric delay in execution of flight tests in eastern Poland was examined. Based on the presented research findings in articles [12-14], it was found that monitoring the state of the ionosphere for air operations is indispensable and necessary.

The aim of this article was to specify an impact of the ionospheric delay in order to determine the aircraft coordinates. In the work the authors used the Klobuchar model, SBAS EGNOS model and the global ionospheric model GIM in the IONEX format for checking the impact of the ionosphere delay on the GPS kinematic data. In particular, the article presents results of an impact of the ionospheric delay on accuracy of the GPS positioning in aviation. The computations exploited real observations and navigation data from an on-board GPS receiver mounted in a Cessna 172. The solution to the problem of modelling the ionospheric delay in the GPS kinematic measurements, presented in the article, is extremely interesting and may be used on a larger scale in air tests.

\section{The research method}

In order to determine the aircraft coordinates, the SPP code method was used as a primary and universal technique of the GPS positioning in 
aviation. The mathematical model of the SPP code method is shown below [15]:

$$
\begin{aligned}
C 1= & \rho+c \cdot(d t r-d t s)+\operatorname{Ion}+ \\
& + \text { Trop }+ \text { TGD }+\operatorname{Rel}+M p
\end{aligned},
$$

where:

$C 1$ - code observations on the L1 frequency in GPS system (expressed in metres),

$c$ - speed of light (expressed in $\mathrm{m} / \mathrm{s}$ ),

$\rho$-geometric distance between the satellite and a receiver on the L1 frequency in GPS system (expressed in metres),

$\rho=\sqrt{\left(X_{\text {rec }}-X_{\text {sat }}\right)^{2}+\left(Y_{\text {rec }}-Y_{\text {sat }}\right)^{2}+\left(Z_{\text {rec }}-Z_{\text {sat }}\right)^{2}}$, $\left(X_{\text {rec }}, Y_{\text {rec }}, Z_{\text {rec }}\right)$ - coordinates of the aircraft in $\mathrm{XYZ}$ geocentric coordinates,

$\left(X_{\text {sat }}, Y_{\text {sat }}, Z_{\text {sat }}\right)$ - satellite coordinates in the GPS system,

$d t r$ - receiver clock bias in the GPS system (expressed in seconds),

$d t s$ - satellite clock bias in the GPS system (expressed in seconds),

Ion - ionosphere delay in the GPS system (expressed in metres),

Trop - troposphere delay in the GPS system (expressed in metres),

$T G D$ - Time Group Delay in the GPS system (expressed in metres),

Rel - relativistic effect in the GPS system (expressed in metres),

$M p$ - multipath effect and measurement noise in the GPS system (expressed in metres).

In Equation (1), the ionospheric delay is referred to as a standard in aircraft positioning by means of the Klobuchar model, which reduces the effect of the ionospheric impact by merely $50-60 \%$ [16]. Therefore, it is necessary to make a precise application of the ionospheric model to improve the performance of aircraft coordinates. The ionosphere delay in Klobuchar model is described as:

$$
\text { Ion }=\left\{\begin{array}{c}
{\left[5 \cdot 10^{-9}+\sum \alpha_{n} \cdot \phi_{m}^{n} \cdot\left(1-\frac{X_{I}^{2}}{2}+\frac{X_{I}^{4}}{24}\right)\right] \cdot F,\left|X_{I}\right| \leq 1.57} \\
5 \cdot 10^{-9} \cdot F,\left|X_{I}\right| \leq 1.57
\end{array}\right.
$$

where:

$\alpha_{n}$ - coefficients of the ionosphere delay from Broadcast ephemeris,

$f_{m}^{n}$ - geomagnetic latitude of ionosphere pierce point,

$X_{I}$ - phase of the ionospheric delay,

$F$ - the mapping function.

One solution to this problem is to exploit the SBAS model for the EGNOS system, which relies on a regular grid (GRID), $5^{\circ}$ by $5^{\circ}$ of one mesh unit [17]. Values of the ionospheric corrections in the SBAS model are retransmitted in real time from EGNOS satellites to the onboard GPS receiver in the universal EMS format. Efficiency of the SBAS ionospheric model is considerably higher than in the Klobuchar model. The ionosphere delay in the SBAS model is described as:
Ion $=M F \cdot \sum w_{n} \cdot V T E C_{n}$,

where:

$M F$ - mapping function,

$w_{n}$ - weight, function of distance between the GRID coordinates and current ionosphere pierce point coordinates

$V T E C_{n}$ - Vertical TEC at GRID SBAS coordinates.

In precise geodetic measurements, the IONEX format is exploited. It contains data of the global ionospheric model GIM in the form of ionosphere maps $2.5^{\circ}$ by $5^{\circ}$ of one mesh unit [18]. Efficiency of this model in geodetic solutions remains at a level of $80-90 \%$. Thus, translating the ionospheric IONEX format into air navigation may prove crucial in improving the designation of aircraft coordinates. The ionosphere delay in the IONEX model is described as below:

Ion $=M F \cdot \sum w_{n} \cdot V T E C_{n}$,

where:

$k$ - coefficient of time rate, $k=\frac{d t}{d T}=\frac{T_{i}-t}{T_{i}-T_{o}}$, $t$ - current time epoch,

$\left(T_{i}, T_{0}\right)$ - reference time epoch of VTEC GRID maps, $V_{T E C_{n}}$ - Vertical TEC at GRID maps from IONEX file.

Impact of ionosphere on the aircraft positioning is visible in conducting navigation in the horizontal LNAV plane. Therefore, the ionospheric delay exerts an impact on determination of the aircraft horizontal coordinates. It has a direct influence during the aircraft take-off and landing at an airport. Thus, the ionospheric delay is a key navigation parameter in aircraft positioning.

\section{The research test}

In the framework of the research test, authors made a simulation of impact of the ionospheric delay on designation of an aircraft position. The computations exploited real observations and the GPS navigation data from an on-board GNSS receiver mounted in the Cessna 172 [19]. The Cessna 172 executed a test flight around the military airport EPDE in Deblin. In the framework of the conducted simulation, authors determined the aircraft position, using different models of the ionospheric delay, i.e. the Klobuchar model, SBAS EGNOS model and the global model GIM in the IONEX format. The research used: - the RINEX observation file with the GPS code measurements,

- the GPS navigation file,

- the file from the EGNOS correction in the EMS format, - the IONEX file with ionosphere maps.

In the first step, the aircraft position was determined, using the Klobuchar model from the GPS navigation message. In the second case, the aircraft position was determined, using the SBAS EGNOS ionospheric model within the format of EMS corrections. In the third case, 
the aircraft position was determined, using the global ionosphere model GIM as a part of the universal IONEX format. The computations of the aircraft position were made in the RTKLIB v.2.4.3 programme in the RTKPOST library. In the computing strategy in the RTKPOST library, the following were used [20]:

- positioning method: single,

- elevation mask: $5^{\circ}$,

- $\quad$ source of ionospheric adjustments: on-board ephemeris Klobuchar model, SBAS model, IONEX format,

- source of tropospheric correction: Saastamoinen model,

- source of ephemeris data and satellite clocks data: on-board ephemeris data,

- coordinate frame: XYZ geocentric coordinates,

- mean error of pseudorange a priori: $1 \mathrm{~m}$,

- type of observations: code on L1 frequency,

- weighting: in the function of the elevation angle: applied,

- maximum DOP coefficient: 30 ,

- observation interval: $1 \mathrm{~s}$.

\section{Results and discussion}

The designated aircraft coordinates in the SPP code solution for different ionospheric models were compared to a precise reference position in order to determine the accuracy of the GPS positioning in aviation. The reference position of the aircraft was determined using the RTK-OTF differential technique for accurate GPS phase observations [21]. The reference position was designated in the Trimble Total Control v.2.7 programme. The coordinates of the aircraft reference position were also specified at a 1-second interval in the geocentric XYZ frame.

Within the conducted investigations, the authors analysed the impact of the ionosphere model on accuracy of the GPS positioning in aviation. Therefore, the accuracy of the GPS positioning was determined, taking into account an impact of an individual ionospheric model on designating the aircraft coordinates. The accuracy of the GPS positioning was specified as [22]:

- $\quad$-for the X component as an absolute value of formula:

$d X=\left\{\begin{array}{l}\left|X_{S P P}^{\text {Klobuchar }}-X_{R T K-O T F}\right| \\ \left|X_{S P P}^{S B P}-X_{R T K-O T F}\right| \\ \left|X_{S P P}^{I O N E X}-X_{R T K-O T F}\right|\end{array}\right.$,

where:

$X_{S P P}^{\text {Klobuchar }}$ - X coordinate of aircraft based on the SPP code solution with the Klobuchar model, see Equation (1),

$X_{S P P}^{S B A S}$ - X coordinate of aircraft based on the SPP code solution with SBAS model, see Equation (1),

$X_{S P P}^{I O N E X}$ - X coordinate of aircraft based on the SPP code solution with the IONEX model, see Equation (1),

$X_{R T K-O T F}$ - X coordinate of aircraft based on the RTK-OTF differential solution, reference coordinate of aircraft, $d X$ - accuracy of aircraft positioning along the $\mathrm{X}$ axis.
- for the Y component as an absolute value of formula:

$d Y=\left\{\begin{array}{l}\mid \begin{array}{l}Y_{S P P}^{K l o b u c h a r}-Y_{R T K-O T F} \mid \\ \left|Y_{S P P}^{S B A S}-Y_{R T K-O T F}\right| \\ \left|Y_{S P P}^{I O N E}-Y_{R T K-O T F}\right|\end{array},\end{array}\right.$,

where:

$Y_{S P P}^{\text {Klobuchar }}$ - Y coordinate of aircraft based on the SPP code solution with the Klobuchar model, see Equation (1),

$Y_{S P P}^{S B A S}$ - Y coordinate of aircraft based on the SPP code solution with SBAS model, see Equation (1),

$Y_{S P P}^{I O N E X}$ - Y coordinate of aircraft based on the SPP code solution with the IONEX model, see Equation (1),

$Y_{R T K-O T F}$ - Y coordinate of aircraft based on the RTK-OTF differential solution, reference coordinate of aircraft,

$d Y$ - accuracy of aircraft positioning along the $\mathrm{Y}$ axis.

- for the $\mathrm{Z}$ component as an absolute value of formula:

$d Z=\left\{\begin{array}{l}\left|Z_{S P P}^{\text {Klobuchar }}-Z_{R T K-O T F}\right| \\ \left|Z_{S P P}^{S B A}-Z_{R T K-O T F}\right| \\ \left|Z_{S P P}^{I O N E X}-Z_{R T K-O T F}\right|\end{array}\right.$,

where:

$Z_{S P P}^{\text {Klobuchar }}$ - Z coordinate of aircraft based on the SPP code solution with the Klobuchar model, see Equation (1), $Z_{S P P}^{S B A S}-\mathrm{Z}$ coordinate of aircraft based on the SPP code solution with SBAS model, see Equation (1), $Z_{S P P}^{I O N E X}-\mathrm{Z}$ coordinate of aircraft based on the SPP code solution with the IONEX model, see Equation (1),

$Z_{\text {RTK-OTF }}$ Z $\mathrm{Z}$ coordinate of aircraft based on the RTK-OTF differential solution, reference coordinate of aircraft,

$d Z$ - accuracy of aircraft positioning along the $\mathrm{Z}$ axis.

Figure 1 shows accuracy of the GPS positioning along the $\mathrm{X}$ axis for different ionospheric models, based on Equation (5). In the case of using the Klobuchar model, the GPS positioning accuracy ranges from $0.3 \mathrm{~m}$ to $9.1 \mathrm{~m}$, with the value of arithmetic mean being equal to $4.6 \mathrm{~m}$. In the case of using the SBAS model, the GPS positioning accuracy is between $0.1 \mathrm{~m}$ and $11.1 \mathrm{~m}$, with the value of arithmetic mean being equal to $4.0 \mathrm{~m}$. However, in the case of using the global model in the IONEX format, the GPS positioning accuracy ranges from $0.1 \mathrm{~m}$ to $5.8 \mathrm{~m}$, with the value of arithmetic mean being equal to $1.3 \mathrm{~m}$. Based on the obtained research results it can be observed that exploiting the SBAS model increased the positioning accuracy by approximately $13 \%$ in relation to using the Klobuchar model in the SPP code method. In addition, using the IONEX model increased the positioning accuracy by approximately $72 \%$ in relation to the exploitation of the Klobuchar model in the SPP code method.

Figure 2 shows accuracy of the GPS positioning along the $\mathrm{Y}$ axis for different ionospheric models, based on Equation (6). In the case of using the Klobuchar model, the GPS positioning accuracy ranges from $0.1 \mathrm{~m}$ to $2.6 \mathrm{~m}$, with the value of arithmetic mean being equal to $0.5 \mathrm{~m}$. In the case of using the SBAS model, the GPS positioning accuracy is between $0.1 \mathrm{~m}$ and $2.1 \mathrm{~m}$, with the value of arithmetic mean being equal to $0.4 \mathrm{~m}$. However, in the case of using the global model in the IONEX format, the GPS positioning accuracy ranges from $0.1 \mathrm{~m}$ to $2.1 \mathrm{~m}$, with the value of arithmetic mean being equal to $0.4 \mathrm{~m}$. Based on the 


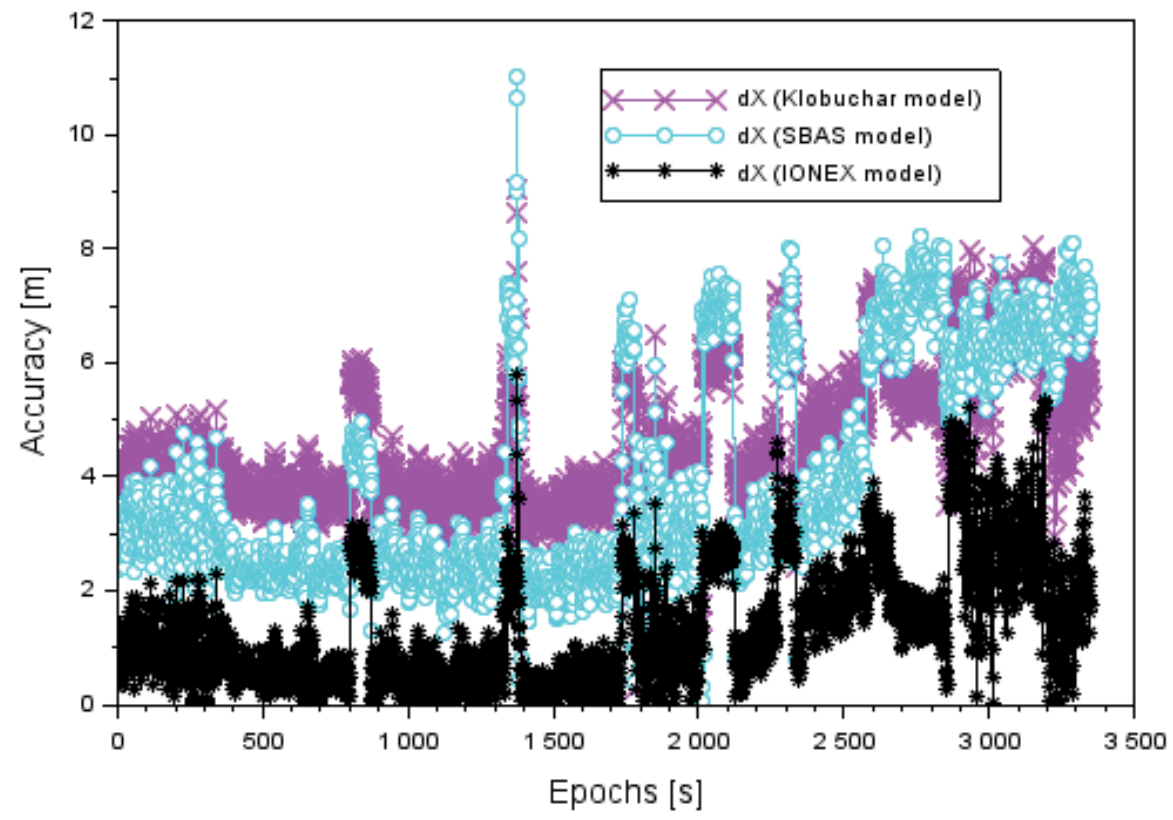

Figure 1 Accuracy of aircraft positioning along the $X$ axis

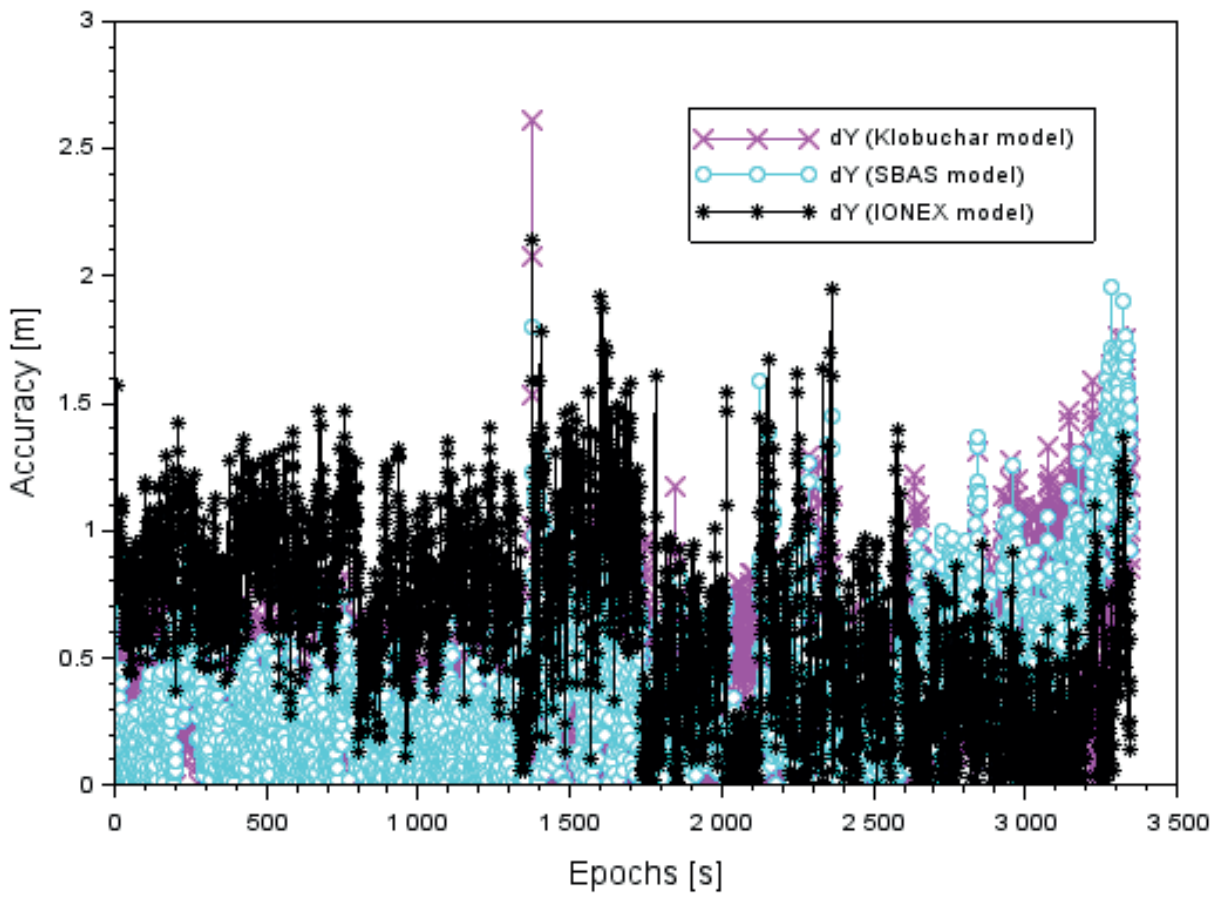

Figure 2 Accuracy of aircraft positioning along the $Y$ axis

obtained research results it can be observed that exploiting the SBAS model increased the positioning accuracy by approximately $20 \%$ in relation to using the Klobuchar model in the SPP code method. In addition, using the IONEX model increased the positioning accuracy by approximately $20 \%$ in relation to the exploitation of the Klobuchar model in the SPP code method.

Figure 3 shows accuracy of the GPS positioning along the $\mathrm{Z}$ axis for different ionospheric models, based on Equation (7). In the case of using the Klobuchar model, the GPS positioning accuracy ranges from $0.3 \mathrm{~m}$ to $5.3 \mathrm{~m}$, with the value of arithmetic mean being equal to $3.1 \mathrm{~m}$. In the case of using SBAS model, the GPS positioning accuracy is between $0.1 \mathrm{~m}$ and $5.8 \mathrm{~m}$, with the value of arithmetic mean being equal to $1.6 \mathrm{~m}$. However, in the case of using the global model in the IONEX format, the GPS positioning accuracy ranges from $0.1 \mathrm{~m}$ to $+5.7 \mathrm{~m}$, with the value of arithmetic mean being equal to $2.2 \mathrm{~m}$. Based on the obtained research results it can be observed that exploiting the SBAS model increased the positioning accuracy by approximately $47 \%$ in relation to using the Klobuchar model in the SPP code method. In addition, using the IONEX model increased 


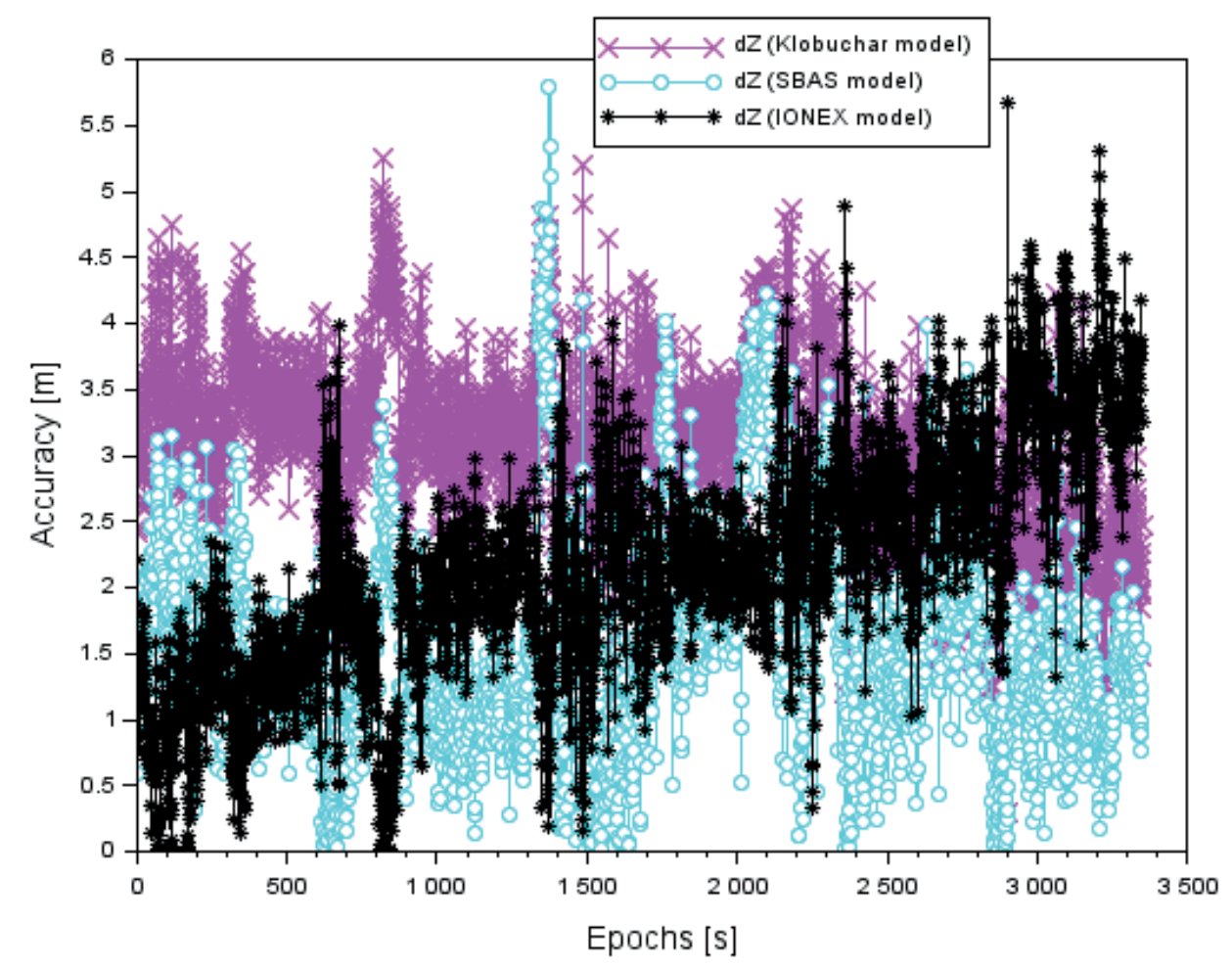

Figure 3 Accuracy of aircraft positioning along the $Z$ axis

Table 1 RMS error for the aircraft position in the XYZ geocentric coordinates

\begin{tabular}{cccc}
\hline & Klobuchar model & SBAS model & IONEX model \\
\hline Coordinate X [m] & 4.8 & 4.3 & 1.7 \\
Coordinate $Y(\mathrm{~m})$ & 0.5 & 0.5 & 0.7 \\
Coordinate $\mathrm{Z}[\mathrm{m}]$ & 3.1 & 1.8 & 2.4 \\
\hline
\end{tabular}

the positioning accuracy by approximately $29 \%$ in relation to the exploitation of the Klobuchar model in the SPP code method.

After specifying the accuracy, authors determined the RMS errors of the aircraft position for the obtained results of parameters $(\mathrm{dX}, \mathrm{dY}, \mathrm{dZ})$ as shown below [23]:

$$
\left\{\begin{array}{l}
R M S d X=\sqrt{\frac{\left[d X^{2}\right]}{N}} \\
R M S d Y=\sqrt{\frac{\left[d Y^{2}\right]}{N}} \\
R M S d Z=\sqrt{\frac{\left[d Z^{2}\right]}{N}}
\end{array}\right.
$$

where:

RMSdX - total RMS error along the $\mathrm{X}$ axis on the flight path, $R M S d Y$ - total RMS error along the Y axis on the flight path, $R M S d Z$ - total RMS error along the $\mathrm{Z}$ axis on the flight path, $N$ - number of determinations of aircraft position.

Results of the RMS errors in the geocentric XYZ frame are shown in Table 1. For the application of the Klobuchar model, the RMS errors of the aircraft position range from $0.5 \mathrm{~m}$ to $4.8 \mathrm{~m}$. For SBAS model, the RMS errors of the aircraft position range from $0.5 \mathrm{~m}$ to $4.3 \mathrm{~m}$. For the IONEX model, the RMS errors of the aircraft position range from $0.7 \mathrm{~m}$ to $2.4 \mathrm{~m}$. Based on Table 1 , the RMS parameter is the smallest for e application of the IONEX model. In addition, the RMS parameter is the highest for the Klobuchar model.

In the next stage of the research, authors defined a shift in the aircraft position in the 2D plane and 3D space, as illustrated below [24-25]:

$$
\left\{\begin{array}{l}
2 D-\text { error }=\sqrt{d X^{2}+d Y^{2}} \\
3 D-\text { error }=\sqrt{d X^{2}+d Y^{2}+d Z^{2}},
\end{array}\right.
$$

where:

$2 D$ - error - shift in aircraft position in the horizontal 2D plane on the flight path,

$3 D$ - error - shift in aircraft position in 3D space on the flight path.

Figure 4 shows a shift in the aircraft position in the horizontal $2 \mathrm{D}$ plane. Therefore, the value of the parameter 2D-error was specified based on the obtained findings (dX, dY, dZ). For application of the Klobuchar model, the shift in the aircraft position in the horizontal 2D plane ranges from $0.7 \mathrm{~m}$ to $9.4 \mathrm{~m}$. Then, for the application of the SBAS model, the shift in the aircraft position in the horizontal 2D plane ranges from $0.5 \mathrm{~m}$ to $11.2 \mathrm{~m}$. In addition, for the application of the IONEX model, the shift in the aircraft position in the horizontal 2D plane is between $0.1 \mathrm{~m}$ and $6.2 \mathrm{~m}$. Based on values of the parameter $2 \mathrm{D}$-error it can be concluded that 


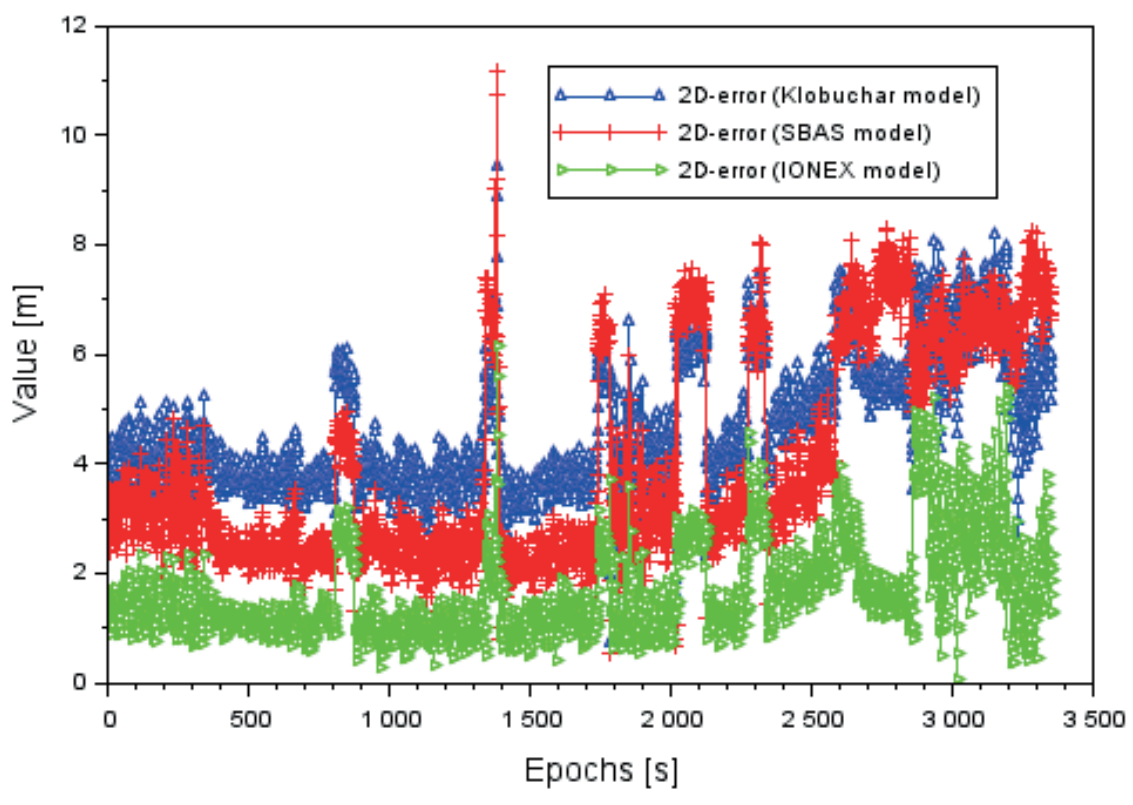

Figure 4 Displacement of the aircraft position in the $2 D$ horizontal plane

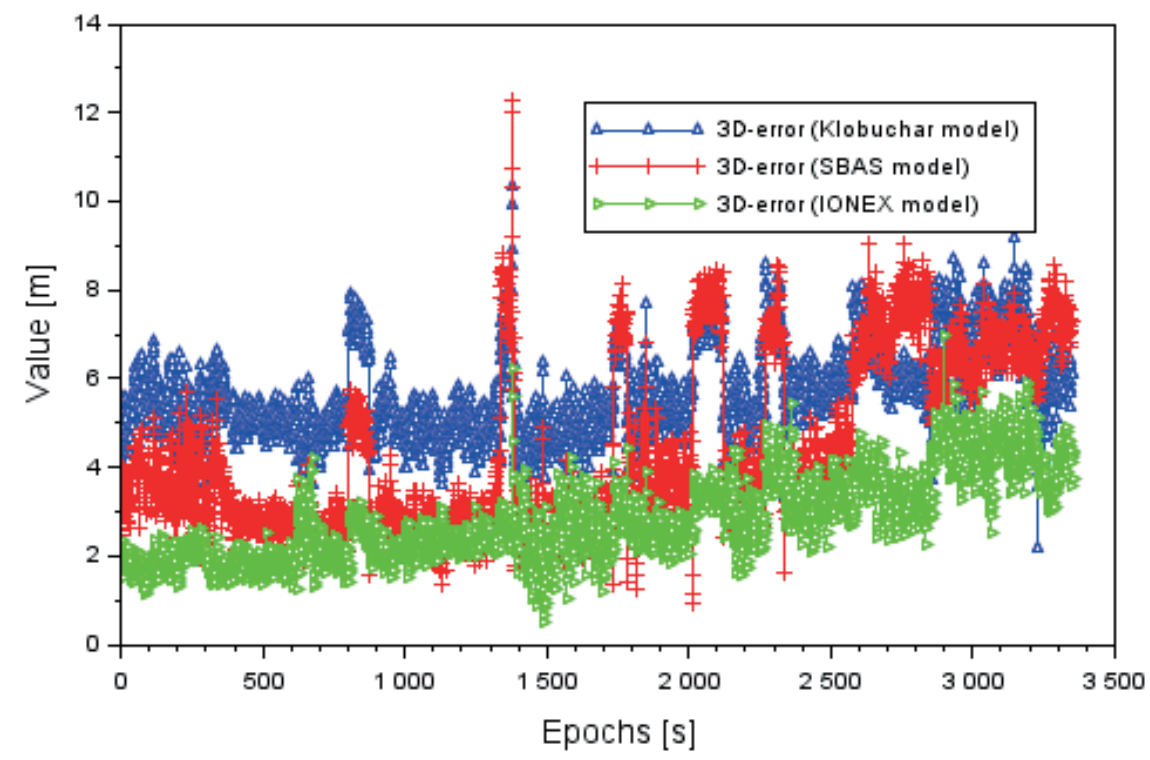

Figure 5 Displacement of the aircraft position in the $3 D$ space

the smallest dispersion of results is for the application of the IONEX model and the largest for the SBAS model.

Figure 5 shows a shift in the aircraft position in the $3 \mathrm{D}$ space. Therefore, the value of the parameter 3D-error was specified based on the obtained findings (dX, dY, dZ). For the application of the Klobuchar model, the shift in the aircraft position in the $3 \mathrm{D}$ space ranges from $2.2 \mathrm{~m}$ to $10.4 \mathrm{~m}$. Then, for application of the SBAS model, the shift in the aircraft position in the 3D space ranges from $0.9 \mathrm{~m}$ to $12.3 \mathrm{~m}$. In addition for application of the IONEX model, the shift in the aircraft position in 3D plane is between $0.5 \mathrm{~m}$ and $7.0 \mathrm{~m}$. Based on values of the parameter 3D-error it can be concluded that the smallest dispersion of results is for application of the IONEX model and the largest for the SBAS model.

\section{Conclusions}

The article describes results of research concerning specification of an impact of the ionospheric delay on determining the aircraft coordinates. The computations exploited the real observation and navigation GPS data from an on-board GNSS receiver. In the course of the conducted research, a number of computer simulations were made with regard to determination of the impact of the ionospheric correction in the SPP code solution. In order to determine the position of the aircraft, the SPP code method in the software RTKLIB v.2.4.3 in the RTKPOST library was used. In the SPP code method, three different ionosphere models were used, i.e. the Klobuchar model from the 
on-board GPS message, the SBAS model from the EMS format in the EGNOS system and the global ionospheric model GIM in the IONEX format. The designated aircraft position using different ionosphere models in the SPP code method was compared to an accurate reference position determined in the RTK-OTF differential technique. Based on the conducted investigations, it was found that:

- $\quad$ application of the SBAS and IONEX models increases the accuracy of the SPP code positioning accordingly by $72 \%$ for coordinate $\mathrm{X}, 20 \%$ for coordinate $\mathrm{Y}$ and
$47 \%$ for the coordinate $\mathrm{Z}$ in relation to the Klobuchar method,

- $\quad$ application of the SBAS and IONEX models causes the smallest shift in aircraft coordinates in relation to the accurate reference position,

- the SBAS and IONEX model can be used to determine the ionospheric delay in air navigation,

- the SBAS and IONEX models can be used to reduce the ionosphere delay and improve the aircraft position in air navigation.

\section{References}

[1] HOFMANN-WELLENHOF, B., LICHTENEGGER, H., WASLE, E. GNSS - global navigation satellite systems: GPS, GLONASS, Galileo and more. Wien, Austria: Springer Wien New York, 2008. ISBN 978-3-211-73012-6.

[2] SEO, J. Overcoming ionospheric scintillation for worldwide GPS aviation. PhD thesis. Stanford, CA: Stanford University, 2010.

[3] COLOMBO, O. L, HERNANDEZ-PAJARES, M., JANSSEN, V., GARCIA-RIGO, A. Comprehensive ionospheric delay modelling for single-frequency GNSS precise positioning: first steps. In: IGS Workshop : proceedings. 2016.

[4] WEBSTER, I. R. Regional model for the prediction of ionospheric delay for single frequency users of the Global Positioning System. Technical report no. 166. New Brunswick: Department of Geodesy and Geomatics Engineering, University of New Brunswick, 1993.

[5] OUZEAU, C, MACABIAU, C., ROTURIER, B., MABILlEAU, M., AZOUlAI, L., LEVAN, J., BESSE, F. Ionospheric delay estimation in a single frequency mode for Civil Aviation. In: 21st International Technical Meeting of the Satellite Division of the Institute of Navigation ION GNSS 2008 : proceedings. 2008. P. 1148-1158.

[6] VENKATA RATNAM, D. Estimation and analysis of user IPP delays using bilinear model for satellite-based augmented navigation systems. Aviation [online]. 2013, 17(1), p. 65-69. ISSN 1648-7788, eISSN 1822-4180. Available from: https://doi.org/10.3846/16487788.2013.805864

[7] DATTA-BARUA, S., LEE, J., PULlEN, S., LUO, M., ENE, A., QIU, D-S., ZHANG, G., ENGE, P. Ionospheric threat parameterization for local area global-positioning-system-based aircraft landing systems. Journal of Aircraft [online]. 2010, 47(4), p. 1141-1151. eISSN 1533-3868. Available from: https://doi.org/10.2514/1.46719

[8] HARRIS, I. L., MANNUCCI, A. J., IIJIMA, B. A., LINDQWISTER, U. J., MUNA, D., PI, X., WILSON, B. D. Ionospheric specification algorithms for precise GPS-based aircraft navigation. Radio Science [online]. 2001, 36(2), p 287-298. eISSN 1944-799X. Available from: https://doi.org/10.1029/1999RS002428

[9] YOSHIHARA, T, FUJII, N., SAITO, A. A Study of the ionospheric effect on GBAS (Ground-Based Augmentation System) using the GPS nation-wide network date in Japan. In: National Technical Meeting of the Institute of Navigation : proceedings. 2004. p. 502-511.

[10] SAITO, S., SUNDA, S., LEE, J., PULLEN, S., SUPRIADI, S., YOSHIHARA, T., TERKILDSEN, M., LECAT, F. Ionospheric delay gradient model for GBAS in the Asia-Pacific Region. GPS Solutions [online]. 2017, 21, p. 1937-1947. ISSN 1080-5370, eISSN 1521-1886. Available from: https://doi.org/10.1007/s10291-017-0662-1

[11] SAITO, S. Ionospheric effects on GBAS and mitigation techniques. In: Workshop on Ionospheric Data Collection, Analysis and Sharing this Support GNSS Implementation : proceedings. ENRI. 2011.

[12] KRASUSKI, K., WIERZBICKI, D. The impact of atmosphere delays in processing of aircraft's coordinates determination. Journal of KONES [online]. 2016, 23(2), p. 209-214. ISSN 1231-4005. Available from: https://doi.org/10.5604/12314005.1213594

[13] GRUNWALD, G., CIECKO, A., BAKULA, M., KAZMIERCZAK, R. Examination of GPS/EGNOS integrity in north-eastern Poland. EIT Radar, Sonar and Navigation [online]. 2016, 10(1), p. 114-121. ISSN 1751-8784, eISSN 1751-8792. Available from: https://doi.org/10.1049/iet-rsn.2015.0053

[14] GRZEGORZEWSKI, M., SWIATEK, A., OSZCZAK, S., CIECKO, A., CWIKLAK, J. Study of EGNOS safety of life service during the period of solar maximum activity. Artificial Satellites [online]. 2012, 47, p. 137-145. eISSN $2083-6104$. Available from: https://doi.org/10.2478/v10018-012-0019-5

[15] SANZ SUBIRANA, J., JUAN ZORNOZA J. M., HERNANDEZ-PAJARES M. Fundamentals and algorithms. Vol. 1. In: GNSS data processing. Noordwijk, Netherlands: ESTEC, ESA Communications, 2013. ISBN 978-92-9221-886-7, p. 139-144.

[16] XU, G., XU, J. GPS theory, algorithms and applications [online]. 3. Ed. Berlin Heidelberg: Springer Verlag, 2016. ISBN 978-3-662-50365-2. Available from: https://doi.org/10.1007/978-3-662-50367-6

[17] International Civil Aviation Organization Asia and Pacific Office. SBAS safety assessment guidance related to anomalous ionospheric conditions. Ed 1.0. 2016. Adopted by APANPIRG/27. 
[18] SCHAER, S. Mapping and predicting the Earth's ionosphere using Global Positioning System. PhD thesis. Zurich, 1999.

[19] KRASUSKI, K. Aircraft positioning using SPP method in GPS system. Aircraft Engineering and Aerospace Technology [online]. 2018, 90(8), p. 1213-1220. ISSN 0002-2667. Available from: https://doi.org/10.1108/AEAT-03-2017-0087

[20] RTKLIB ver. 2.4.3 Manual, RTKLIB: an open source program package for GNSS positioning - TAKASU T. [online]. 2013. Available from: http://www.rtklib.com/prog/manual_2.4.2.pdf

[21] CWIKLAK, J., JAFERNIK, H. The monitoring system for aircraft and vehicles of public order services based on GNSS. Annual of Navigation. 2010, 16, p 15-24. ISSN 1640-8632.

[22] KRASUSKI, K., CWIKLAK, J., JAFERNIK, H., Aircraft positioning using PPP method in GLONASS system. Aircraft Engineering and Aerospace Technology [online]. 2018, 90(9), p 1413-1420. ISSN 0002-2667. Available from: https://doi.org/10.1108/AEAT-06-2017-0147

[23] CHAI, T., DRAXLER, R. R. Root mean square error (RMSE) or mean absolute error (MAE)? - Arguments against avoiding RMSE in the literature. Geoscientific Model Development [online]. 2014, 7, p. 1247-1250. ISSN 1991-959X, eISSN 1991-9603. Available from: https://doi.org/10.5194/gmd-7-1247-2014

[24] HENNING, W. User guidelines for single base real time GNSS positioning. Version 2.1. National Geodetic Survey, 2011.

[25] JACOBSEN, K. S., DAHNN, M. Statistics of ionospheric disturbances and their correlation with GNSS positioning errors at high latitudes. Journal of Space Weather and Space Climate [online]. 2014, 4, A27. eISSN 2115-7251. Available from: https://doi.org/10.1051/swsc/2014024

\section{Annex - Nomenclature}

\begin{tabular}{ll}
\hline The abbreviation & The full name \\
\hline GPS & Global Positioning System \\
LPV & Localizer performance with vertical guidance \\
STEC & Slant TEC \\
NPA & Non-Precision Approach \\
APV & Approach with Vertical Guidance \\
GBAS & Ground Based Augmentation System \\
SBAS & Satellite Based Augmentation System \\
EGNOS & European Geostationary Navigation Overlay Service \\
GIM & Global Ionosphere Maps \\
IONEX & The IONospheric EXchange Format \\
SPP & Single Point Positioning \\
XYZ & Global geocentric coordinates \\
EMS & EGNOS Message \\
LNAV & Lateral Navigation \\
GNSS & Global Navigation Satellite System \\
EPDE & ICAO airport code \\
RINEX & Receiver Independent Exchange System \\
DOP & Dilution of Precision \\
RTK-OTF & Real Time Kinematic - On The Fly \\
RMS & Root Mean Square \\
VTEC & Vertical TEC \\
\hline
\end{tabular}

